\title{
Unexpected Relationships between Thermal and Radiative Energy Transfer
}

\author{
Thorstein 0. Seim1, Borgar T. Olsen ${ }^{2,3}$ \\ ${ }^{1}$ Former Senior Research Scientist at Nycomed Pharma, Oslo, Norway \\ ${ }^{2}$ Former Research Fellow at Max-Planck-Institute for Physiological and Clinical Research, Munich, Germany \\ ${ }^{3}$ Former Research Scientist at Telenor (Televerkets) Research Department, Fornebu, Norway \\ Email: thorstein.seim@gmail.com
}

How to cite this paper: Seim, T.O. and Olsen, B.T. (2020) Unexpected Relationships between Thermal and Radiative Energy Transfer. Atmospheric and Climate Sciences, 10, 639-651.

https://doi.org/10.4236/acs.2020.104033

Received: September 29, 2020

Accepted: October 27, 2020

Published: October 30, 2020

Copyright (c) 2020 by author(s) and Scientific Research Publishing Inc. This work is licensed under the Creative Commons Attribution International License (CC BY 4.0).

http://creativecommons.org/licenses/by/4.0/

\section{(c) (i) Open Access}

\begin{abstract}
A simple experiment is described where the IR (infrared) radiation level is kept constant while the temperature of an IR absorbing and a non-absorbing solid object are changed. The two objects, made from black-painted and highly polished $\mathrm{Al}$ foil envelopes, respectively, are placed in a chamber where the temperature is controlled. When heated by the surrounding air the black object becomes about $40 \%$ colder than the non-IR absorbing object! However, when the two objects are cooled by the surrounding air, the black becomes ca. $40 \%$ warmer than the non-IR absorbing object (and the surrounding air). This effect was surprising to us, and it gave us an opportunity to quantify the relationship between IR radiation flow and thermal energy flow. The unexpected large value of the (Fourier) thermal conductivity coefficient was found to be the reason for the reduced warming/cooling of the black object. The interaction between radiative and thermal energy transfer, when an IR absorbing object (like the surface of the Earth) is warmed, should be included in the climate models used by the Intergovernmental Panel on Climate Change (IPCC), since the global land temperature is measured in the air above Earth's surface. This leads to ca. $15 \%$ of the temperature increase predicted by the climate models.
\end{abstract}

\section{Keywords}

IR Radiation, Thermal Energy Transfer, Global Warming Models

\section{Introduction}

When the Sun shines on the Earth's surface, it heats up. The hot ground then absorbs/emits energy in two ways: 
1) Thermal energy: According to the second law of thermodynamics, thermal energy flow can only go from the hotter to the colder object. The thermal energy flow $\Delta E_{T}$ is given by Fourier's law for heat conduction [1], which can be formulated as follows:

$$
\Delta E_{T}=k\left(T_{2}-T_{1}\right)
$$

where $T_{2}$ and $T_{1}$ are the temperatures in Kelvin of two objects and the constant $\mathrm{k}$ indicates the conductivity of thermal energy transfer.

2) Radiative energy: The relationship between the infrared (IR) radiation energy flow $E_{I R}$ in $\mathrm{W} / \mathrm{m}^{2}$ from a black body and its temperature $T$ is given by the Stefan-Boltzmann law [2]:

$$
E_{I R}=\sigma T^{4}
$$

where $T$ is the temperature in Kelvin and $\sigma=5.67 \times 10^{-8} \mathrm{~W} /\left(\mathrm{m}^{2} \mathrm{~K}^{4}\right)$ is the Stefan-Boltzmann constant. Based on this law the IR radiation energy transfer $\Delta E_{I R}$ between two black body objects, with temperatures $T_{A}$ and $T_{B}$, can be expressed as:

$$
\Delta E_{I R}=\sigma\left(T_{A}^{4}-T_{B}^{4}\right)
$$

or by derivation of Equation (2) with $T$ equal average of $T_{A}$ and $T_{B}$ :

$$
\Delta E_{I R}=4 \sigma T^{3} \Delta T
$$

Both objects emit IR radiation and absorb it, but the net energy flow always goes from the hot to the cold object.

Thermodynamics and electromagnetic radiation physics are two different disciplines, as illustrated by Equations (1) and (3). But when solid objects and gases are exposed to both IR radiation and thermal energy flow we get both energy flows simultaneously. This is a complex situation and difficult to study. In physical experiments, it is therefore sensible to vary one parameter, while the others are kept constant. We decided to keep the level of IR radiation level as constant as possible, while we varied the temperature of two objects with different properties. One object should absorb most of the incoming IR radiation but the other one should not absorb, but instead reflect, almost all IR radiation. These two objects should be placed in an environment where the air temperature could be raised or lowered. To optimize the influence of thermal heating of the objects their mass (and thus their heating capacity) should be low but their surfaces should be large. For the object that absorbs (and emits) IR radiation, this will maximize the interaction between radiative and thermal energy transfer. (Note that using a very thin body that absorbs all incident rays was introduced as a definition of a black body by Gustav Kirchhoff in 1860 [3]).

\section{Methods}

\section{Experiment with Constant IR Radiation Level}

In principle, it should not be possible to heat objects without also increasing the IR radiation from the object. See the Stefan-Boltzmann law. But we managed 
this by using materials that do not react according to this law, i.e. thin, polished aluminum (Al) foil! The two objects were made of $\mathrm{Al}$ foil, in the form of two 6 $\mathrm{cm} \times 7 \mathrm{~cm}$ envelopes where a thermocouple is placed inside each of them. (The envelopes were flat). One envelope was painted mat black on the outside. This envelope will then absorb (and emit) most of the incoming IR radiation. (Black paint, containing carbon, was used to ensure high absorption for IR radiation). The other envelope was not painted and its polished Al foil surface will then reflect nearly all of the incoming IR radiation.

Thermocouples, type $\mathrm{K}$, were used to measure the temperature of the envelopes because the size of their temperature sensitive element is small, approx. 1 $\mathrm{mm}$. The thermocouples, placed inside the envelopes, are then quickly heated to the same temperature as the envelope.

In order to create an environment for the objects where the air can be heated or cooled, a box with length, width and height of $30 \mathrm{~cm} \times 20 \mathrm{~cm} \times 20 \mathrm{~cm}$ was made. It had a framework of thin white plastic rails. The walls and the top of the box were made of thin LDPE (low-density polyethylene) plastic foil, which transmits nearly all of the IR radiation from the surrounding room [4]. (During heating of the air in the box, the hot air is prevented from flowing upwards, so that the experiment is not affected by heat convection). The box was placed on a table in the middle of the room, so that the (constant) IR radiation from the surrounding walls and roof was evenly distributed from all directions. The two envelopes were mounted inside the box. To measure the temperature of the air in the box (at the same height as the envelopes), an extra thermocouple was installed and placed between the envelopes. In order for this thermocouple to respond more quickly to temperature changes, it was flattened to increase the contact surface with the surrounding air. The box, the envelopes, the thermocouple and the temperature reading instruments are shown in Figure 1.

To heat the air in the box, a metal heating plate was made. The nominal heating power was $60 \mathrm{~W}$, but the input voltage could be adjusted by a variac. The plate was placed under the box in a recess in a $5 \mathrm{~cm}$ thick styrofoam plate. The size of the plate was as large as the bottom of the box. The heating plate was covered with polished $\mathrm{Al}$ foil, as shown in the figure. This foil screens the direct IR radiation from the heating element below. This was tested by heating the plate from $16^{\circ} \mathrm{C}$ to $60^{\circ} \mathrm{C}$ (measured by placing a thermocouple on top of the plate under the Al-foil). This increased IR radiation from the $\mathrm{Al}$ foil at the bottom of the box by only approx. $1.1 \%$, demonstrating that the polished $\mathrm{Al}$ foil mainly reflects, not emit, IR radiation.

The average temperature for the Earth is close to $16^{\circ} \mathrm{C}$, which determined the choice of room temperature in the experiment. For a room temperature of $16^{\circ} \mathrm{C}$ or $289 \mathrm{~K}$ the IR radiation level is held constant at $396 \mathrm{~W} / \mathrm{m}^{2}$, according to the Stefan-Boltzmann's law. (To keep the IR level constant in the room, the lighting was also dimmed).

The three thermocouples showed some slight difference in measured temperature. They were therefore calibrated before the experiment began. 


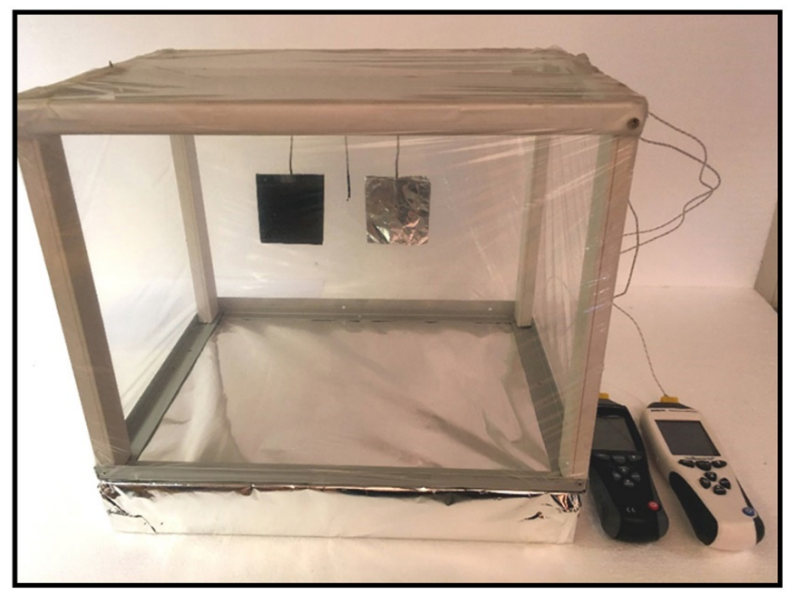

Figure 1. Photo of the experimental arrangement. The photo shows the box with walls and roof made from thin plastic foil, the black and the polished envelopes and an extra thermocouple placed between them. The measuring instruments for the three thermocouples are located to the right of the box. Under the box, we have placed the heating plate, wrapped in polished Al-foil.

\section{Results}

\subsection{Heating with Halogen Lamp}

Before conducting a constant IR level experiment, we simulated what happens when the Sun warms the Earth's surface. For this, we used a $500 \mathrm{~W}$ halogen lamp, placed $60 \mathrm{~cm}$ from the box. The black envelope is heated by the light from the lamp in the same way the ground is heated by the Sun. The polished $\mathrm{Al}$ envelope reflects most of the light and IR radiation from the lamp and we expected it to heat up significantly less than the black envelope. This is verified in Figure 2. The diagram shows the temperatures of the two envelopes during 5 minutes of heating with the lamp. We see that the black envelope needed less than 3 minutes to reach a steady rise in temperature. The polished $\mathrm{Al}$ envelope reflects most of the IR radiation and is mainly heated by collisions with the air-molecules in the box. It therefore heats up more slowly and with an almost constant temperature gradient. The temperature of the black envelope continues to rise when the air in the box gets warmer, indicating that it is heated both by radiation and thermal conduction.

\subsection{Heating the Air in the Box with a Heating Plate}

Then the lamp was removed. After the air in the box was again equal to the room temperature of $16^{\circ} \mathrm{C}$, the heating plate under the box was switched on. However, when we heat the air in the box with the heating plate, we get an unexpected result! See Figure 3, showing the heating of the two envelopes. Although the black envelope absorbs thermal energy from warm air and the (constant) IR radiation from the surroundings, the temperature increases considerably more slowly than for the polished $\mathrm{Al}$ envelope! 
After 35 minutes, the current to the heating plate was turned off and measurement continued until the temperature stabilized after approx. 45 minutes.

We also looked at the relationship between the temperature rise for the air in the box and the temperature for the polished $\mathrm{Al}$ envelope. In order to increase the temperature range, we increased the voltage to the heating plate and let the heating continue for one hour. Figure 4 shows that the polished $\mathrm{Al}$ envelope is heating as quickly as the air in the box.

From Figure 3, we see that the temperature difference between the envelopes first increases but then it seems to stabilize. But will it remain stable, or will the difference gradually diminish with time? To check this, a new experiment was made where the heating was extended to two hours. But the temperature difference between the envelopes did not decrease but remained constant.

After heating, the heating plate current was switched off and the temperature measured while the temperature in the air dropped back to room temperature. Only when the temperature in the box is back to room temperature does a new equilibrium arise. At equilibrium, the temperature is the same for the two envelopes, and equal to the temperature in the room and in the box.

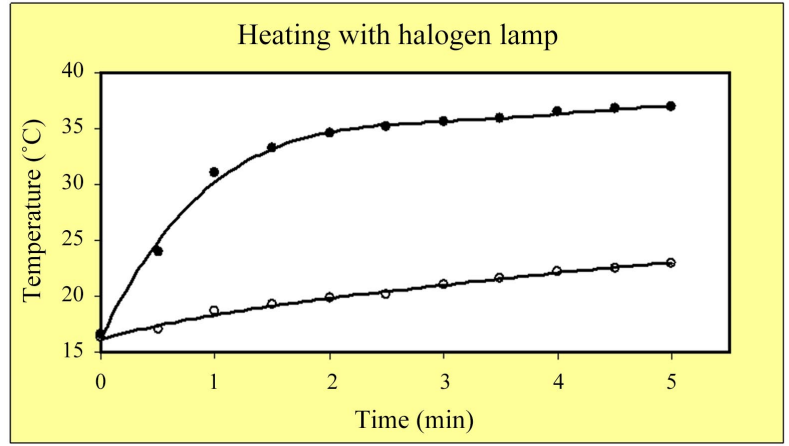

Figure 2. Simulating sunlight heating of the two envelopes. Light from a $500 \mathrm{~W}$ halogen lamp, placed $60 \mathrm{~cm}$ from the box, heats the black envelope (black circles) significantly faster than the envelope of polished Al-foil envelope (open circles).

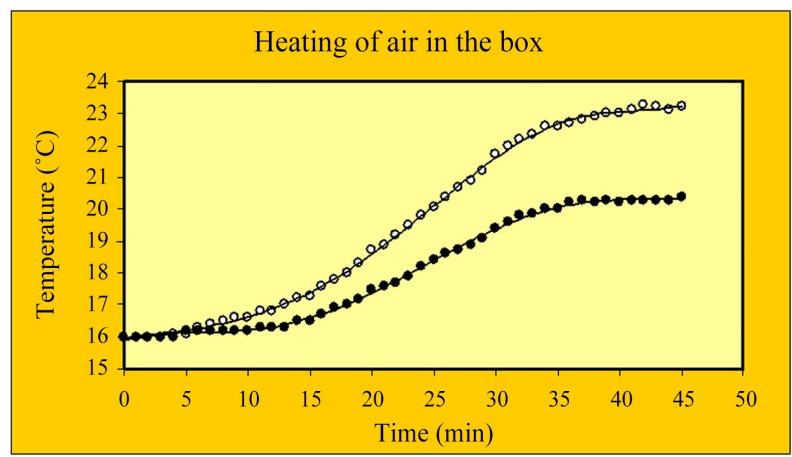

Figure 3. Heating the air in the box with the metal plate placed under the box. As the air in the box heats up, the temperature of the black envelope (black circles) increases significantly more slowly than that of the polished $\mathrm{Al}$ envelope (open circles). 


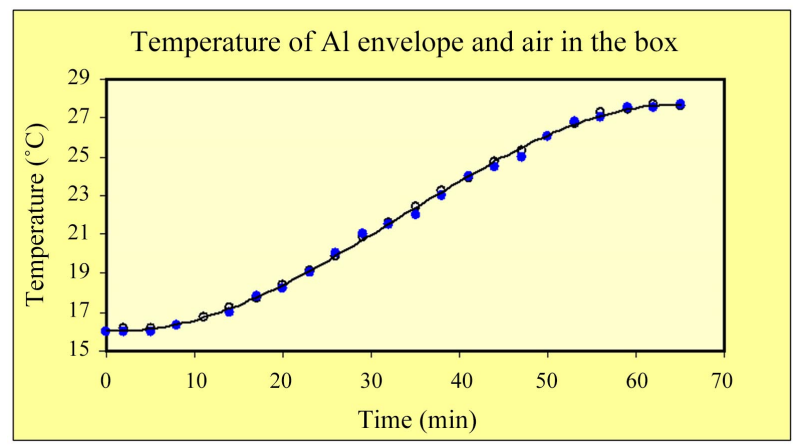

Figure 4. Heating the air and $\mathrm{Al}$ foil envelope. Temperature for the air (blue circles) in the box and for the polished $\mathrm{Al}$ envelope (open circles) follow the same curve when heated with the heating plate under the box.

From the data in Figure 3, we can show that the temperature drops for the black envelope (relative to the air) in an almost linear way when the air temperature changes. This is shown in Figure 5 for the heating of the air in the box. When the heating plate was turned off the air temperature in the box and that of the black envelope drops and follows the same trend line as shown in Figure 5.

\subsection{Control of the Heating Experiment}

To check for possible sources of error, the following was done:

1) Differences in envelope temperatures during heating may be due to warmer air where polished $\mathrm{Al}$ envelope is placed. The envelopes were therefore inter-changed, but the result was the same as shown in Figure 3 and Figure 4.

2) The thermocouples in the envelopes could measure the temperature inaccurately and give different results. But switching thermocouples for the two envelopes produced the same result.

3) When one envelope is painted black, the mass of the envelope increases, which may cause slower heating. This was checked by making a new polished $\mathrm{Al}$ envelope, using two layers of $\mathrm{Al}$ foil. Then the mass of the envelope increased significantly more than that of the black-painted envelope. This too gave almost the same result as shown in Figure 3 and Figure 4.

4) Can heating be affected by the size of the envelopes? This was tested by replacing the polished $\mathrm{Al}$ envelope with a $14 \mathrm{~cm} \times 12 \mathrm{~cm}$ black-painted envelope. But the black envelope, with eight times larger surface area, was heated in the same way as the small black envelope.

5) To measure IR radiation a detector containing a thermopile was constructed [5]. IR radiation from the black envelope was measured during heating and cooling of the envelope. The temperature of the envelope (measured by the thermocouple inside it) was found to be equal to the temperature computed by Equation (2), i.e. as expected from the Stefan-Boltzmann law.

\subsection{Cooling the Air in the Box}

To cool the air in the box, a metal pan was placed on top of the box (See Figure 6). The vessel was filled with cold water and ice cubes. The pan was covered with Al 
foil on the outside (and inside) to keep the IR-level constant. This provided an effective method for cooling the air in the box. The result is shown in Figure 7. The cooling is so effective that it only takes approx. 4 minutes before the temperature stabilizes. But what is surprising is that the temperature of the black envelope is then approx. 3.5 degrees higher than the temperature of the polished $\mathrm{Al}$ envelope!

(When the mass of the polished $\mathrm{Al}$ envelope was doubled, the temperature drop was similar to that in Figure 7, but the temperature drop at the start of the fast cooling was slightly delayed, due to the higher mass of the envelope).

Finally, we have gathered the result of heating and cooling in one figure. Here we have plotted the temperature of the black envelope as a function of the temperature of the air in the box. Cooling, shown in Figure 7, proceeded so rapidly that it resulted in temperature gradients in the air in the box. However, after cooling, the pan with ice and water was removed so that the temperature could slowly increase to room temperature, thus reducing the uneven temperature distribution in the box. These cooling data were used in Figure 8. Data from the heating (red dots) and the cooling (blue dots) are also shown in Figure 8 and we see that both heating and cooling follow approximately the same linear function. (Note that by removing the pan the experimental setup is identical for both cooling and heating of the air temperature in the box).

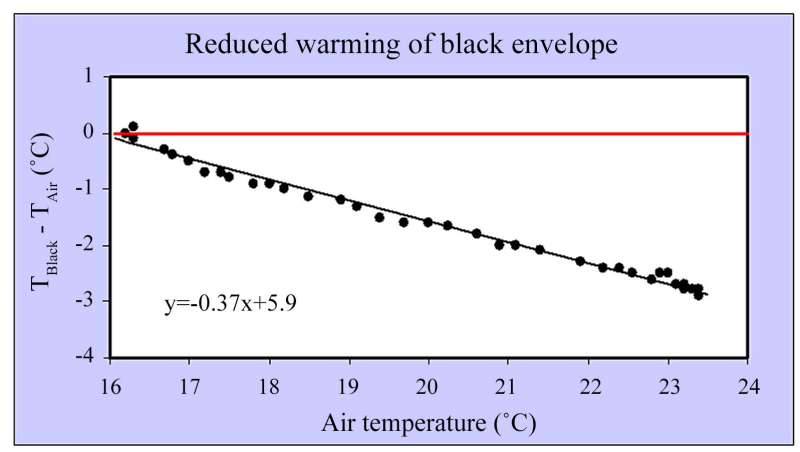

Figure 5. Temperature difference between the black envelope and air (black circles), as function of air temperature. The red line shows what we expected, i.e. that the black envelope should have the same temperature as the ambient air. The formula for the trend line (thin black line) is also included.

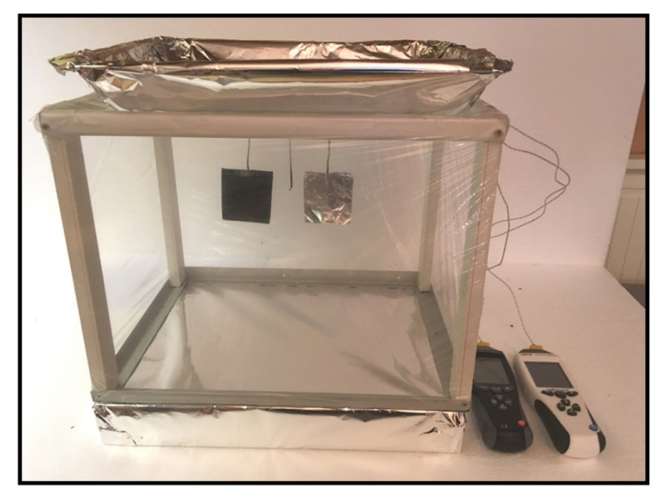

Figure 6. Cooling the air. The photo shows the setup used to cool the air in the box with ice and cold water in a metal pan, placed on top of the box. 


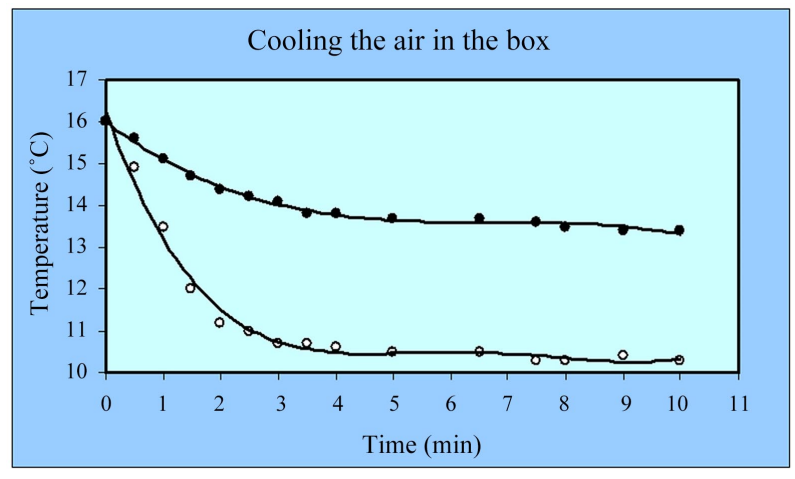

Figure 7. Cooling the envelopes. Black circles: black envelope. Open circles: polished $\mathrm{Al}$ envelope.

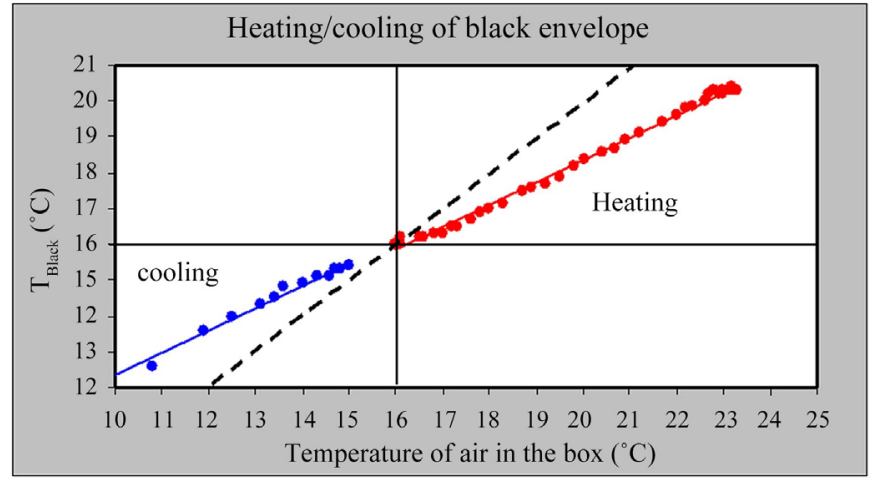

Figure 8. Summary of the results. Black envelope temperature as a function of air temperature. Red circles show temperature for black envelope when the ambient air in the box is warmer than for the surroundings (at $16^{\circ} \mathrm{C}$ ), while blue circles show temperature for the black envelope when the ambient air in the box is colder than the room temperature. The dashed line shows the temperature of the air in the box.

\section{Calculations and Discussion}

\subsection{Heating the Air in the Box}

When the heating plate is turned on the air temperature $T_{A I R}$ in the box starts to rise. This increases the thermal energy transfer and rises the temperature $T_{B}$ of the black envelope. A higher $T_{B}$ increases the emitted IR energy (proportional to $T_{B}^{4}$ ). From Figure 3, we see that the heating stabilizes after ca. 60 minutes. Then the absorbed thermal energy and emitted radiation energy for the black envelope are equal. From data presented in Figure 5, we can now quantify the radiative and thermal energy flow for the black envelope. According to Stefan-Boltzmann law the emitted IR energy is controlled by the temperature of the black envelope. When its temperature increases from its initial temperature of $T_{1}=16$ to $T_{2}=$ $21^{\circ} \mathrm{C}$, then the increase in emitted IR-radiation flow is found from Equation (4) to be $\Delta E_{I R}=28.1 \mathrm{~W} / \mathrm{m}^{2}$.

The thermal energy flow $\Delta E_{T}$ is driven by the temperature difference between the black envelope and the air in the chamber, where $T_{A I R}=24^{\circ} \mathrm{C}$ and the black envelope $T_{B}=21^{\circ} \mathrm{C}$. From Equation (1) we get 


$$
\Delta E_{T}=k\left(T_{A i r}-T_{B}\right)
$$

or $\Delta E_{T}=k^{*} 3 \mathrm{~W} / \mathrm{m}^{2}$. In the steady-state situation, where the energy flow received and emitted by the black envelope is equal, we get $\Delta E_{I R}=\Delta E_{T}$. This gives us the value of $k=9.4 \mathrm{~W} /\left(\mathrm{m}^{2} \mathrm{~K}\right)$.

\subsection{Cooling the Air in the Box}

When the air in the box is cooled below $16^{\circ} \mathrm{C}$ the energy flow can be computed from the data shown in Figure 8. When the air temperature $T_{A I R}$ is $10^{\circ} \mathrm{C}$ the temperature $T_{B}$ of the black envelope is $12.3^{\circ} \mathrm{C}$. The increased IR energy absorbed by the envelope, when the temperature is reduced from $16^{\circ} \mathrm{C}$ to $12.3^{\circ} \mathrm{C}$, is $\Delta E_{I R}=19.86 \mathrm{~W} / \mathrm{m}^{2}$.

Thermal energy for the warmer $\left(12.3^{\circ} \mathrm{C}\right)$ envelope is lost to the colder $\left(10^{\circ} \mathrm{C}\right)$ surrounding air in the box. This energy loss can be computed from Equation (1). Again we assume that absorbed energy must be equal to lost energy. With a temperature difference of 2.3 degrees the constant $\mathrm{k}$ is calculated to be 8.6 $\mathrm{W} /\left(\mathrm{m}^{2} \mathrm{~K}\right)$. From heating of the air in the box, we got $k=9.4 \mathrm{~W} /\left(\mathrm{m}^{2} \mathrm{~K}\right)$. The average value of $k$ is then $9.0 \mathrm{~W} /\left(\mathrm{m}^{2} \mathrm{~K}\right)$.

\subsection{Interaction between Radiative and Thermal Energy Transfer}

From the close to linear responses shown in Figure 8, we see that we obtain the thermal conductivity coefficient $k \sim 9 \mathrm{~W} /\left(\mathrm{m}^{2} \mathrm{~K}\right)$ for all measured temperatures. The slow heating (and cooling) of the air temperature during the experiment keep the energy transfer process close to steady state for all measurements and the received energy is equal to lost energy for the black envelope. The computed energy flows are also independent of the surface area of the envelope. The same value of $\mathrm{k}$ was obtained by an eight times larger area of the black envelope.

The equilibrium condition, when $\Delta E_{I R}=\Delta E_{T}$, highlights the difference between heating a black object by thermal and radiative energy transfer. The energy flow needed to heat or cool the black envelope one degree is about 5.5 $\mathrm{W} /\left(\mathrm{m}^{2} \mathrm{~K}\right)$ for the radiation energy transfer and about $9 \mathrm{~W} /\left(\mathrm{m}^{2} \mathrm{~K}\right)$ for the thermal energy transfer. The change in IR energy flow per degree temperature change is then only $5.6 / 9=0.62$ of the value of the change in thermal energy flow per degree.

In Equation (1) there is a linear relationship between energy transfer $\Delta E_{T}$ and temperature. For Equation (4) the energy transfer $\Delta E_{I R}$ is almost linear in the limited experimental temperature range of $10^{\circ} \mathrm{C}$ to $24^{\circ} \mathrm{C}$. So, shifting equilibrium from $16^{\circ} \mathrm{C}$, within the temperature range of $10^{\circ} \mathrm{C}$ to $24^{\circ} \mathrm{C}$, we believe will still result in $k$ close to $9 \mathrm{~W} /\left(\mathrm{m}^{2} \mathrm{~K}\right)$. So we believe that this value closely describes the relationship between the IR energy transfer and the thermal energy transfer for a blackbody surface.

\section{Consequences for Climate Models}

The climate models, used by IPCC, assume that it is mainly the increase of IR 
radiation from $\mathrm{CO}_{2}$ that is the cause of Global Warming [6]. Increased IR-radiation from $\mathrm{CO}_{2}$ in the atmosphere, absorbed by the ground, will raise the temperature of the air above the ground [7] [8], which in turn leads to anthropogenic global warming [9]. However, some scientists questions this theory [10].

The thermometers, used to measure global temperature, are positioned 1.25 2 meters above the ground [11]. Since it is not the temperature of the ground that is measured but the air above it, the interaction between radiative heating and thermal heating should be included in the models. This is attempted in the analysis presented below:

In the climate models, the relationship between the concentration $c$ of $\mathrm{CO}_{2}$ in the air and the increased $I R$ energy flow $\Delta F$ in $\mathrm{W} / \mathrm{m}^{2}$ (called radiative Forcing) radiated back to the ground, is given by the equation developed by Arrhenius [12]:

$$
\Delta F=\alpha \operatorname{Ln}\left(\frac{c}{c_{0}}\right)
$$

where $c_{0}$ is the concentration of $\mathrm{CO}_{2}$ in pre-industrial times, usually set at 278 ppm (parts per million) of the atmosphere. The constant $\alpha$ is set at $5.35 \mathrm{~W} / \mathrm{m}^{2}$ by the climate scientists [13]. With the present value of $\mathrm{CO}_{2}$ concentration of $\mathrm{c}$ close to $410 \mathrm{ppm}$, we get the value of $\Delta F=2.1 \mathrm{~W} / \mathrm{m}^{2}$.

The relationship between radiative Forcing $\Delta F$ by increased $\mathrm{CO}_{2}$ and the resulting global warming $\Delta T$ of the air temperature is given in the models presented by IPCC [14] as:

$$
\Delta T=\lambda \Delta F
$$

where the constant $\lambda$ is the climate sensitivity. The climate sensitivity is very difficult to quantify, due to the complex global interplay between ground and ocean temperatures, air movements, clouds etc. The result is a wide spread of values for $\lambda$ in the different climate models. Some models use a value of $\lambda=0.5^{\circ} \mathrm{C}$ $/\left(\mathrm{W} / \mathrm{m}^{2}\right)$ [14], while other studies operate with larger values [15]. Using the lowest value of $\lambda=0.5^{\circ} \mathrm{C} /\left(\mathrm{W} / \mathrm{m}^{2}\right)$, Equation (7) gives $\Delta T=1.04^{\circ} \mathrm{C}$ for todays concentration of $\mathrm{CO}_{2}$.

However, if we only consider how much IR radiation from increased $\mathrm{CO}_{2}$ alone warms the ground, it seems that $\lambda$ has a too large value. If we assume that the temperature of the ground will increase as indicated by the Stefan-Boltzmann law, then we can use Equation (4) to calculate $\Delta T$ :

$$
\Delta T=\Delta F /\left(4 \sigma T^{3}\right)
$$

where $4 \sigma T^{3} \mathrm{~W} /\left(\mathrm{m}^{2} \mathrm{~K}\right)=5.47 \mathrm{~W} /\left(\mathrm{m}^{2} \mathrm{~K}\right)$ when $T=289 \mathrm{~K}$, which give $\lambda$ a value of $0.18^{\circ} \mathrm{C} /\left(\mathrm{W} / \mathrm{m}^{2}\right) . \Delta T$ then becomes $0.18^{\circ} \mathrm{C} \times 2.1^{\circ} \mathrm{C}=0.38^{\circ} \mathrm{C}$.

NOTE: Since the ground is not a "perfect" black body, some of the IR radiation from $\mathrm{CO}_{2}$ that hits it will be reflected, thus reducing $\Delta T$ further.

Strictly speaking Equation (8) is valid only for a black object placed in a vacuum. With air above a black object $\Delta T$ will be less. 
Let us assume we increase the IR radiation by $\Delta F=2.1 \mathrm{~W} / \mathrm{m}^{2}$ and study the resulting rise of the ground temperature. When the temperature of the ground starts to rise, then the IR radiation output from the ground will also increase. This increased radiation will not heat the air since it is transparent to IR radiation. So less of the input $\Delta F$ energy flow is left to rise the air temperature. The temperature rise will be larger than zero, but smaller than $0.38^{\circ} \mathrm{C}$.

When the ground temperature has risen 0.2 degrees (i.e. about half of $0.38^{\circ} \mathrm{C}$ ), the IR output from the ground has increased by $1.2 \mathrm{~W} / \mathrm{m}^{2}$, according to Equation (2). Energy flux left to increase the thermal heat transfer to the air is then $\Delta E_{T}=0.9 \mathrm{~W} / \mathrm{m}^{2}$.

This result can be further studied in an example. From temperature measurements we found that, when the Sun heated the ground to about $25^{\circ} \mathrm{C}$, the temperature of the air 1.5 meters above the ground was about $20^{\circ} \mathrm{C}$. Let us assume that the air above the ground is kept in place by a box with thin plastic walls, like the one used in the experiment (resulting in no energy loss due to convection). Emitted IR energy flow from the ground is then found by Equation (2) to be $447.15 \mathrm{~W} / \mathrm{m}^{2}$. Emitted thermal energy transfer from the ground is found from Equation (1) to be $E_{T}=45 \mathrm{~W} / \mathrm{m}^{2}$. The energy received from the Sun must be equal to the emitted energy from the ground and be equal to $492.15 \mathrm{~W} / \mathrm{m}^{2}$.

Then we add IR radiation from $\mathrm{CO}_{2}$, equal to $2.1 \mathrm{~W} / \mathrm{m}^{2}$. As the ground temperature rises, increased thermal energy flow will start to warm the air. But the available thermal energy flow will decrease. We have computed the temperature increase that will maximize the available energy for heating the air and found that, when the ground temperature is $25.14^{\circ} \mathrm{C}$, the available energy flow for thermal heating is at a maximum of $1.26 \mathrm{~W} / \mathrm{m}^{2}$. Since $9 \mathrm{~W} / \mathrm{m}^{2}$ heats the air $1.0^{\circ} \mathrm{C}$ then $1.26 \mathrm{~W} / \mathrm{m}^{2}$ heats it $0.14^{\circ} \mathrm{C}$, i.e. exactly as expected from the increased ground temperature! However, this is significantly lower than the value found from the climate models.

NOTE: If the box is removed the warm air inside will move upward, due to convection, and further reduce the heating of the air above the ground.

\section{Conclusion}

We have presented an experiment that is very easy to perform and can easily be repeated, even by physics students in high school. The result was very surprising and reveals the relationship between radiative and thermal energy transfer. The result may also have a significant impact on the climate models, used by the IPCC, since the experiment shows that the heating an IR absorbing object (like the Earth's surface, warmed by the Sun) might warm the air significantly less than predicted by the climate models.

\section{Acknowledgements}

We would like to thank Stein Bergsmark for valuable advice about the interaction between radiative and thermal energy transfer. 


\section{Funding}

This work was not supported by fundings.

\section{Conflicts of Interest}

The authors declare no conflicts of interest regarding the publication of this paper.

\section{References}

[1] Fourier, J. (1822) Théorie analytique de la chaleur, Firmin Didot. Cambridge University Press, Cambridge, 2009. https://doi.org/10.1017/CBO9780511693229

[2] Alonso, M. and Finn, E.J. (1968) Fundamental University Physics. Vol. 3, Library of Congress Catalog Car No. 68-10828, 11.

[3] Kirchhoff, G. (1860) On the Relation between the Radiating and Absorbing Powers of Different Bodies for Light and Heat. The London, Edinburgh, and Dublin Philosophical Magazine and Journal of Science, 20, 1860. Translated by Guthrie, F. from Annalen der Physik: Vol. 109, 275-301. https://doi.org/10.1080/14786446008642901

[4] Junga, M.R., et al. (2018) Validation of ATR FT-IR to Identify Polymers of Plastic Marine Debris, Including Those Ingested by Marine Organisms. Marine Pollution Bulletin, 127, 704-716. https://doi.org/10.1016/j.marpolbul.2017.12.061 https://tsapps.nist.gov/publication/get_pdf.cfm?pub_id=924694

[5] Data for the Wide-Band IR Detector Used. https://www.te.com/commerce/DocumentDelivery/DDEController?Action=showd oc\&DocId=Data+Sheet\%7FTS105-10L5.5\%7FA\%7Fpdf\%7FEnglish\%7FENG_DS_T S105-10L5.5_A.pdf\%7FG-TPCO-019

[6] Myhre, G.D. and Shindell, D. (2013) Anthropogenic and Natural Radiative Forcing. In: Climate Change 2013: The Physical Science Basis. Contribution of Working Group I to the Fifth Assessment Report of the Intergovernmental Panel on Climate Change, Cambridge University Press, Cambridge, Chapter 8, 659-740. https://www.ipcc.ch/site/assets/uploads/2018/02/WG1AR5_Chapter08_FINAL.pdf

[7] Kiehl, J.T. and Trenberth, K.E. (1997) Earth's Annual Global Mean Energy Budget. Bulletin of the American Meteorological Society, 78, 197-208. https://doi.org/10.1175/1520-0477(1997)078<0197:EAGMEB>2.0.CO;2

[8] Trenberth, K.E., Fasullo, J.T. and Kiehl, J.T. (2009) Earth's Global Energy Budget. Bulletin of the American Meteorological Society, 90, 311-323. https://doi.org/10.1175/2008BAMS2634.1

[9] Pierrehumbert, R.T. (2011) Infrared Radiation and Planetary Temperature. Physics Today, 64, 33-38. https://doi.org/10.1063/1.3541943

[10] Lindzen, R.S. and Choi, Y. (2011) On the Observational Determination of Climate Sensitivity and Its Implications. Asia-Pacific Journal of Atmospheric Sciences, 47, 377-390. https://doi.org/10.1007/s13143-011-0023-x

[11] The World Meteorological Organization (WMO).

[12] Arrhenius, S. (1896) On the Influence of Carbonic Acid in the Air upon the Temperature of the Ground. The London, Edinburgh, and Dublin Philosophical Magazine and Journal of Science, 41, 237-276. https://doi.org/10.1080/14786449608620846

[13] Myhre, G., Highwood, E.J., Shine, K.P. and Stordal, F. (1998) New Estimates of Radiative Forcing Due to Well Mixed Greenhouse Gases. Geophysical Research Let- 
ters, 25, 2715-2718. http://folk.uio.no/gunnarmy/paper/myhre_grl98.pdf https://doi.org/10.1029/98GL01908

[14] Ramaswamy, V. (2001) Scientific Basis TAR 06, Radiative Forcing of Climate Change. https://www.ipcc.ch/site/assets/uploads/2018/03/TAR-06.pdf

[15] Collins, M., Knutti, R., Arblaster, J., Dufresne, J.L., Fichefet, T., Friedlingstein, P., et al. (2013) Chapter 12: Long-Term Climate Change: Projections, Commitments and Irreversibility (PDF). In: Climate Change 2013: The Physical Science Basis. Contribution of Working Group I to the Fifth Assessment Report of the Intergovernmental Panel on Climate Change, Cambridge University Press, Cambridge, 1029-1136. 